\title{
The prevalence of depression amongst outpatients with multimorbidity
}

\author{
Melinda Stanners ${ }^{1^{*}}$, Christopher Barton $^{1}$, Sepehr Shakib $^{2}$, Helen Winefield ${ }^{3}$ \\ ${ }^{1}$ Social Health Science, Flinders University, Adelaide, Australia; ${ }^{*}$ Corresponding Author: melinda.stanners@flinders.edu.au \\ ${ }^{2}$ Clinical Pharmacology, Royal Adelaide Hospital, Adelaide, Australia \\ ${ }^{3}$ Discipline of Psychiatry, University of Adelaide, Adelaide, Australia
}

Received 24 February 2013; revised 26 March 2013; accepted 10 April 2013

Copyright (C) 2013 Melinda Stanners et al. This is an open access article distributed under the Creative Commons Attribution License, which permits unrestricted use, distribution, and reproduction in any medium, provided the original work is properly cited.

\section{ABSTRACT}

Objectives: Depression may be under-diagnosed and under-treated amongst older adults with multiple chronic illnesses. The current study explores the prevalence of depression diagnosis and Geriatric Depression Scale (GDS) symptoms amongst older multimorbid outpatients, and agreement between GDS scores and doctor-diagnosed depression. Method: Deidentified data from the files of $\mathbf{4 5 2}$ patients aged over 64, with chronic conditions present in two or more organ domains, were extracted from the clinical database of a tertiary referral hospital multidisciplinary outpatient clinic in South Australia between 2005 and 2011. Frequency calculations determined the prevalence of depression diagnosis and GDS categories. Logistic regression, cross-tabulation, kappa and ROC graphs explored relationships between variables. Results: A depression diagnosis had been recorded for 71 (15.7\%) patients. Using the recommended cut-off scores for the GDS, 225 (49.8\%) patients met criteria for mild-severe depressive symptoms, and 96 (21.3\%) met criteria for moderate-severe symptoms. Poor agreement was found between doctor diagnosis of depression and a positive screen for depression using a GDS cut-off score of either $5, k=0.112$ ( $p=$ $0.001)$, or $9, k=0.189(p<0.001)$, although logistic regression found an association between severity of depression and depression diagnosis, $\mathrm{OR}=1.15, \mathrm{p}<0.001(\mathrm{Cl}=1.08-1.22)$. Conclusion: A much higher proportion of patients with multimorbidities reported threshold level depression symptoms than had a recorded diagnosis of depression, suggesting that although likelihood of diagnosis increases with symptom severity, depression often goes undetected in this population. Depressions' negative impact on prognosis calls for further investigation of the barriers to screening and diagnosis of depression in multimorbid patients.

Keywords: Multimorbidity; Geriatric Depression Scale; Chronic Disease

\section{INTRODUCTION}

More people are living with chronic illnesses for longer, and the likelihood of developing one or more chronic illnesses increases with age [1]. The relationship between mental health and multiplicity of disease is important as the risk of developing depression increases where two or more chronic conditions are present [2]. When patients present to their clinician with multiple chronic conditions, or "multimorbidity", the treatment of physical symptoms may take precedence over psychological symptoms [3], creating challenges in the detection and management of depression. Additionally, complex symptom profiles create challenges in detecting depression, as physical symptoms such as low energy, poor appetite, weight loss or cognitive decline may be related to depression, or disease, or both [4]. Social symptoms of depression may also be attributed to physical illness [5], leaving clinicians struggling to differentiate between social and psychological issues amongst older adults [6,7]. Reliance on patient reports of psychological symptoms, particularly amongst older patients, may be compromised by stigma related to depression [8]. Consequently it is unsurprising that depression is thought to be under-diagnosed and under-treated amongst older people in Western nations [9-11].

A range of scales have been developed to assist with the diagnostic process, but previous research suggests 
that overlap of physical and psychological symptoms may render diagnostic tools that rely on somatic symptoms unreliable [12,13]. One tool often used in aged populations is the 15-question Geriatric Depression Scale (GDS) developed at Stanford University [14] to screen for symptoms of depression in aged individuals, which has been validated in aged community-dwelling populations [15-17]. A GDS score of 5 has been found to have a sensitivity of $91 \%$ and a specificity of $72 \%$ for depression [18], but neither the scale nor the categorisation scores have been validated in patients with multiple chronic conditions. In light of the challenges of depression diagnosis, exploring the performance of the GDS in multimorbid patients would make a valuable contribution to clinicians concerned about detecting depression in this population.

Whilst multimorbidity is most often defined as two or more chronic conditions [19], disease count does not accurately reflect disease burden [20]; consequently this definition may be less appropriate for use for mental health research. As age-related increases in depression may be attributable to declines in physical health, physical function and perceptions of well-being [21], Fortin et al.'s 2005 definition of multimorbidity as the presence of disease in two or more organ domains may be more appropriate for exploring the relationship between multimorbidity and mental health, and consequently has been applied in the current study.

We aimed to explore the prevalence of depression diagnoses and symptoms in multimorbid community-dwelling outpatients, hypothesising equivalent rates of depression diagnosis and threshold-level depression symptoms as measured by the GDS. We anticipated good agreement between doctor-diagnosed depression and GDS scores.

\section{METHOD}

De-identified data were extracted from the clinic database for 452 patients with multiple chronic conditions referred to a metropolitan multidisciplinary clinic between September 2005 and September 2011. The Multidisciplinary Ambulatory Consulting Service (MACS) clinic provides integrated multidisciplinary care for multimorbid outpatients. Patients complete an extensive selfreport health and lifestyle questionnaire, which includes the 15 question Geriatric Depression Scale (GDS), and the responses are entered into the clinic database. Medications, vitamins and supplements are recorded in the database, as well as chronic conditions and acute health events. Depression diagnoses are recorded in the database if the diagnosis is included in the referral letter from the general practitioner. The current or remitted state of depression is not recorded in the database; nor is whether the diagnosis was given by a general practitioner or psychiatrist.
Chronic conditions were grouped into Cumulative Illness Rating Scale (CIRS) domains [20], with disease present in cardiac, vascular, endocrine, respiratory, renal, neurological, musculo-skeletal, psychiatric and upper GI domains (see Table 1). The psychiatric domain was excluded due to high co-linearity with depression diagnosis. Patients with chronic conditions in two or more domains (not including the psychiatric domain) and a recorded GDS score in their file were included in the data set, but excluded if they had a diagnosis of dementia or if they were less than 65 years of age.

Data were analysed using PASW Statistics Version 18. To estimate the prevalence of depressive symptoms, frequency calculations demonstrated the proportion of patients with a GDS score of greater than or equal to 5 (mildsevere depression) and 9 (moderate-severe depression) respectively [14]. Frequency calculations were also used to explore demographic data and the prevalence of depression diagnoses. Logistic regression was used to explore association of GDS score severity with depression diagnosis. Cross-tabulation, kappa calculations and ROC graph analysis were then applied to explore the agreement between depression diagnosis and GDS categorisation.

Ethics approval for this study was granted by the Royal Adelaide Hospital Ethics Committee. MS was supported by a scholarship from the Faculty of Health Science at the University of Adelaide and a supplementary scholarship from the Clinical Pharmacology unit at the Royal Adelaide Hospital. The authors had full access to all data in the study.

\section{RESULTS}

Demographic data for the 452 eligible patients are described in Table 2. Depression diagnoses were recorded for $15.7 \%$ of patients, with women overrepresented in this group. When the standard GDS scoring categories

Table 1. Disease domains and conditions.

\begin{tabular}{ll}
\hline Domain & Conditions \\
\hline Cardiac & $\begin{array}{l}\text { Atrial fibrillation, heart failure, ischemic heart } \\
\text { disease } \\
\text { Vascular }\end{array}$ \\
$\begin{array}{l}\text { Pulmonary vascular disease, thrombosis, lipids, } \\
\text { hypertension }\end{array}$ \\
Endocrine & Diabetes \\
Musculo-skeletal & Osteoarthritis, osteoporosis, gout, arthritis \\
Renal & Chronic renal failure \\
Respiratory & $\begin{array}{l}\text { Asthma, chronic obstructive pulmonary disease, } \\
\text { sleep apnea }\end{array}$ \\
Upper GI & Gastro-oesophageal reflux disease \\
Neurological & $\begin{array}{l}\text { Parkinson's disease, epilepsy, cardiovascular } \\
\text { disease }\end{array}$ \\
\hline
\end{tabular}


Table 2. Frequency table of demographic, antidepressant, depression and GDS variables $(\mathrm{N}=452)$.

\begin{tabular}{|c|c|c|}
\hline Age & & $\begin{array}{c}\text { Range }=65-98 \text { years } \\
\text { Mean }=79.7(\mathrm{SD}=7.06)\end{array}$ \\
\hline Disease Domain Count & & $\begin{array}{c}\text { Range }=2-8 \\
\text { Median }=4(\mathrm{SE}=0.06)\end{array}$ \\
\hline \multirow{4}{*}{ Gender } & Male & $202(44.7 \%)$ \\
\hline & Female & $250(55.3 \%)$ \\
\hline & Partner Only & $192(42.5 \%)$ \\
\hline & Alone & $138(30.5 \%)$ \\
\hline \multirow[t]{4}{*}{ Living Circumstance } & With Carer & $14(3.1 \%)$ \\
\hline & Other/Unknown & $61(13.5 \%)$ \\
\hline & Other Family Present & 47 (10.4\%) \\
\hline & Non-Smoker & $206(45.6 \%)$ \\
\hline \multirow[t]{4}{*}{ Tobacco Use } & Ex-Smoker & $213(47.1 \%)$ \\
\hline & Smoker & $28(6.2 \%)$ \\
\hline & Male & $32(16.2 \%)$ \\
\hline & Female & $75(31.4 \%)$ \\
\hline \multirow{4}{*}{ Antidepressant Use N = 107 (23.7\%) } & SSRI & 59 (62.8\%) \\
\hline & Tricyclic & $35(37.2 \%)$ \\
\hline & History of Depression & $50(46.7 \%)$ \\
\hline & No History of Depression & 57 (53.3\%) \\
\hline \multirow{4}{*}{ Clinical Depression History N = 71 (15.7\%) } & Male & 25 (12.4\%) \\
\hline & Female & $46(18.4 \%)$ \\
\hline & No Depression & $227(50.2 \%)$ \\
\hline & Mild Depression & $129(28.5 \%)$ \\
\hline \multirow{2}{*}{ GDS Category } & Moderate Depression & $56(12.4 \%)$ \\
\hline & Severe Depression & $40(8.9 \%)$ \\
\hline
\end{tabular}

were applied, approximately half of all patients (49.8\%) scored five or more on the GDS, with $21.2 \%$ scoring in the moderate-severe range ( 9 - 15) for depressive symptoms (Table 2).

One hundred and seven (23.7\%) patients had been prescribed an antidepressant at the time of their first clinic visit, more than half of whom had no diagnosis of depression (Table 2). Women were twice as likely as men to be taking an antidepressant on their first visit to the clinic (Table 2). Antidepressant status data were missing for 16 patients.

Table 3 describes the GDS categorisations for patients with and without depression who did and did not have an antidepressant at their first visit to the clinic. Of the 71 patients with a diagnosis of depression, 50 (72.5\%) were taking an antidepressant. Of the 169 people with no diagnosis of depression and sub-threshold GDS symptoms, $26(13.1 \%)$ were taking an antidepressant upon entry to the clinic. Amongst patients with neither a diagnosis of depression nor an antidepressant prescription, however, 51 (16.4\%) scored in the moderate-severe range of the GDS.
Detailed antidepressant data were available for only 94 patients, with 59 taking selective serotonin reuptake inhibitors (SSRIs) and 35 taking tricyclics antidepressants (TCAs). Comparing antidepressant type between the presence or absence of a diagnosis of depression or anxiety, $33.9 \%$ of SSRI use and $68.6 \%$ of TCA use occurred amongst patients with no recorded history of doctor diagnosis of depression or anxiety (Table 4).

Logistic regression of depression diagnosis and GDS score found a statistically significant association between GDS score and depression diagnosis, OR $=1.15, \mathrm{p}<$ $0.001(\mathrm{CI}=1.08-1.22)$. Of the 71 patients with a diagnosis of depression, 48 patients $(67.6 \%)$ scored 5 or higher on the GDS, with a kappa statistic of $\kappa=0.112$ (p $=0.001$ ) demonstrating poor agreement between a positive screen for mild-severe depression and record of a clinical diagnosis of depression. Of the 381 patients with no diagnosis of depression, 177 (46.5\%) scored five or more on the GDS.

Analyses were repeated with a GDS cut-off of 9 or more (reflecting moderate-severe depression). Of the 71 patients with a clinical diagnosis of depression, only 28 
Table 3. GDS Categorisations for patients with and without depression, compared by antidepressant use at first clinic visit $(\mathrm{N}=436)$.

\begin{tabular}{|c|c|c|c|c|c|c|c|c|c|c|c|c|}
\hline \multirow{3}{*}{ GDS Categorisation } & \multicolumn{6}{|c|}{$\begin{array}{l}\text { No History of Depression } \\
\mathrm{N}=367(84.2 \%)\end{array}$} & \multicolumn{6}{|c|}{$\begin{array}{l}\text { History of Depression } \\
\mathrm{N}=69(15.8 \%)\end{array}$} \\
\hline & \multicolumn{3}{|c|}{$\begin{array}{l}\text { No Antidepressant } \\
\quad \mathrm{N}=310\end{array}$} & \multicolumn{3}{|c|}{$\begin{array}{l}\text { Antidepressant } \\
\quad \mathrm{N}=57\end{array}$} & \multicolumn{3}{|c|}{$\begin{array}{c}\text { No Antidepressant } \\
\mathrm{N}=19\end{array}$} & \multicolumn{3}{|c|}{$\begin{array}{l}\text { Antidepressant } \\
\quad \mathrm{N}=50\end{array}$} \\
\hline & $\mathbf{N}$ & $\begin{array}{l}\text { Column } \\
\%\end{array}$ & $\begin{array}{c}\text { Row } \\
\%\end{array}$ & $\mathbf{N}$ & $\begin{array}{c}\text { Column } \\
\%\end{array}$ & $\begin{array}{c}\text { Row } \\
\%\end{array}$ & $\mathbf{N}$ & $\begin{array}{c}\text { Column } \\
\%\end{array}$ & $\begin{array}{c}\text { Row } \\
\%\end{array}$ & $\mathbf{N}$ & $\begin{array}{c}\text { Column } \\
\%\end{array}$ & $\begin{array}{c}\text { Row } \\
\%\end{array}$ \\
\hline $\begin{array}{l}\text { No Depression } \\
\mathrm{N}=220\end{array}$ & 172 & 55.5 & 86.9 & 26 & 45.6 & 13.1 & 4 & 21.1 & 18.2 & 18 & 36.0 & 81.8 \\
\hline $\begin{array}{l}\text { Mild Depression } \\
\qquad \mathrm{N}=125\end{array}$ & 87 & 28.1 & 82.9 & 18 & 31.6 & 17.1 & 5 & 26.3 & 25.0 & 15 & 30.0 & 75.0 \\
\hline $\begin{array}{c}\text { Moderate Depression } \\
\text { N }=54\end{array}$ & 33 & 10.6 & 82.5 & 7 & 12.3 & 17.5 & 4 & 21.1 & 28.6 & 10 & 20.0 & 71.4 \\
\hline $\begin{array}{l}\text { Severe Depression } \\
\quad \mathrm{N}=37\end{array}$ & 18 & 5.8 & 75.0 & 6 & 10.5 & 25.0 & 6 & 31.6 & 46.2 & 7 & 14.0 & 53.8 \\
\hline
\end{tabular}

Table 4. History of depression and antidepressant type.

\begin{tabular}{ccc}
\hline & No Depression History & Depression History \\
\hline SSRI & $20(33.9 \%)$ & $39(66.1 \%)$ \\
TCA & $24(68.6 \%)$ & $11(31.4 \%)$ \\
\hline
\end{tabular}

patients (39.4\%) had a GDS score of 9 or more, with a kappa statistic of $\kappa=0.189$ ( $\mathrm{p}<0.001$ ) demonstrating poor agreement between a positive screen for moderatesevere depression and a diagnosis of depression. Of the 381 patients with no clinical diagnosis of depression, 68 patients (17.8\%) scored 9 or more on the GDS. An ROC graph (Figure 1) demonstrated poor discriminatory power of depression diagnosis for the GDS, AUC $=0.65$. $\mathrm{p}<0.001$. A cut-off score of 5 had a sensitivity of 0.68 and a specificity of 0.47 , and a cut-off score of 9 had a sensitivity of 0.35 and a specificity of 0.14 .

\section{DISCUSSION}

Contrary to expectations, the GDS cut-off of 5 reflected a prevalence of depressive symptoms in this outpatient clinic population considerably higher than the prevalence of depression diagnosis, which, as hypothesised, exceeded the community prevalence of depression in Australians aged over 65 years of $12.5 \%$ [22]. The weak association between depression diagnosis and GDS categorisation and the poor agreement demonstrated by the ROC curve suggests that the two measures are not evaluating the same phenomenon. More than fifty percent of patients diagnosed with depression and taking an antidepressant still experienced depressive symptoms, suggesting the possibility of under-treatment in this group. Although logistic regression found that severity of depression as measured by GDS score increased the likelihood of having a diagnosis of depression, supporting previous findings from the Hampshire Depression Study [23], a large proportion of patients with high GDS scores did not have a doctor diagnosis of depression, suggesting under-diagnosis in this group.

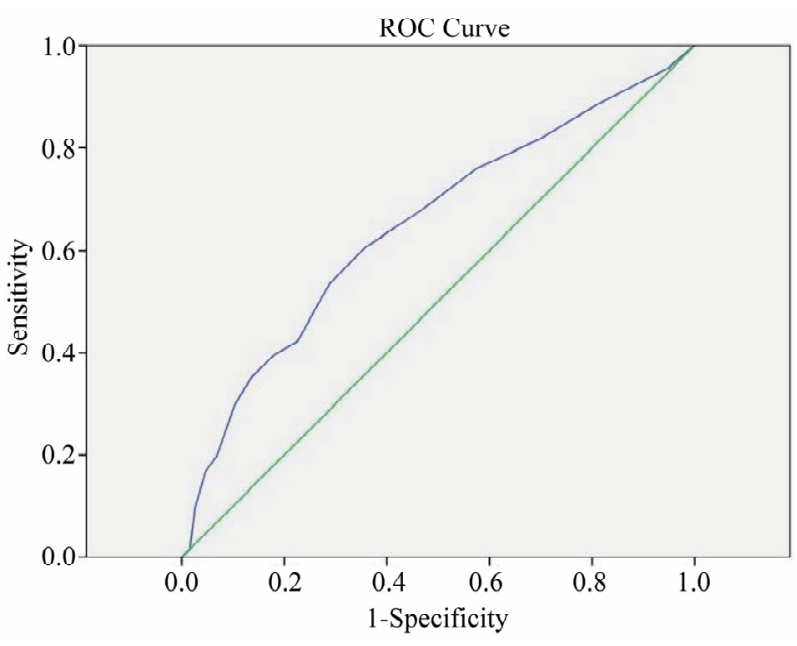

Figure 1. ROC graph of GDS score and depression diagnosis.

The GDS may demonstrate a genuinely high prevalence of depressive symptoms in the older multimorbid demographic, but with a sensitivity of $91 \%$ and a specificity of $72 \%$ for depression [18], a cut-off score of 5 creates risk of obtaining false positives, which may increase in a high-risk population. Considering the poor agreement between GDS and depression diagnosis demonstrated by the ROCs, a cut-off value of 5 may overestimate the prevalence of depressive symptoms, rendering it inappropriate for this population. Somatic or behavioural questions may be affected by the complex symptom profile generated by multiple physical illnesses. Future research should generate ROC graphs using a gold standard diagnostic tool to identify the most appropriate GDS cut-off scores for clinical relevance, and evaluate individual GDS items for their appropriateness in this population. Future research could also evaluate whether other parameters, such as frailty or multimorbidity, predict positive responses to specific questions, with a view to proposing different cut-off scores or removing questions with poor discriminatory ability when used in this population. 
Clinical relevance should be considered when selecting cut-off scores for depression diagnosis in multimorbid patients. Previous research suggests that whilst GPs miss mild cases of depression in the general practice population, the likelihood of being diagnosed with depression increases with severity [23]. Failure to detect mild depression may not affect prognosis, as less severe depression has been found to resolve without detection or intervention in otherwise healthy adults [24]. This assurance cannot, however, be generalised to multimorbid patients. In contrast to Thompson et al.'s 2001 findings, the current study found that sixty-five percent of all patients who scored as severely depressed using the GDS had not been diagnosed with depression, suggesting that severe depression may present differently in older patients with multiple chronic conditions.

Whilst many patients reporting severe depressive symptoms have been neither diagnosed with depression nor prescribed medication, a large proportion of patients without depression diagnosis are taking antidepressants. This may in part be attributable to the prescribing of tricyclic antidepressants (TCAs) for a range of different complaints; the prescription of selective serotonin reuptake inhibitors (SSRIs) to 33.9\% of patients with no history of depression, however, raises questions about medication practices in this population, as SSRIs are usually used only for depression or anxiety. Future exploration of antidepressant prescribing practices in the multimorbid population would be valuable, particularly as patients with severe depressive symptoms remain untreated.

It is noteworthy that almost one third of patients attending the clinic were excluded from the present analyses because they were under 65 years of age (32.5\%). Whilst validated in older populations, no studies have examined the applicability of the GDS to patients under 65. As no age classification has been applied to the term "geriatric" it may be appropriate to consider it a description of an individual's health status and physical function, and examine the applicability of the GDS in younger multimorbid patients. Additionally, with most studies of multimorbidity restricted to participants aged 65 and older, the large percentage of younger multimorbid patients excluded suggests that a substantial proportion of the multimorbid population is being overlooked. This supports previous findings that multimorbidity affects adults of all ages [2,25], and suggests that future multimorbidity research should include younger multimorbid patients.

\section{Limitations}

Depression is not diagnosed at the multidisciplinary clinic; consequently, inclusion of a diagnosis of depression in the clinic database was reliant on referral letters. Neither the recency, nor the source (general practitioner, psychiatrist), nor the method (screening questionnaire, clinical judgement or interview) of depression diagnosis were documented, making differentiation between historical and current depression, or single depressive episodes and chronic recurrent depression, impossible. There may be inconsistencies both in diagnostic definition and criteria, as the diagnostic label does not capture the breadth of depression experience and severity across the patient group. Future research exploring the experiences of depression diagnosis amongst multimorbid patients is necessary to shed light on the diagnostic process in this population.

\section{CONCLUSION}

This study revealed that depressive symptoms may not be recognised in this population, as although nearly half of patients with multiple chronic conditions treated at a multi-disciplinary outpatient clinic screened positive for depressive symptoms using the Geriatric Depression Scale (GDS), the rate of doctor-diagnosed depression was only slightly higher than the community average. The poor agreement between depression diagnosis and symptom severity suggests a high level of undiagnosed depression in this population, and inconsistent association of depression diagnosis with antidepressant prescription raises questions about prescription practices amongst multimorbid patients. Future research is needed to clarify the true prevalence of depressive symptoms in this complex and vulnerable population and barriers to screening and diagnosis in primary care.

\section{REFERENCES}

[1] Australian Bureau of Statistics (2009) National Health Survey: Summary of results 2007-2008 A.B.o. Statistics, Commonwealth of Australia, Canberra.

[2] Gunn, J.M., Ayton, D.R., Densley, K., Pallant, J.F., Chondros, P., Herrman, H.E. and Dowrick, C.F. (2012) The association between chronic illness, multimorbidity and depressive symptoms in an Australian primary care cohort. Social Psychiatry and Psychiatric Epidemiology, 47, 175-184. doi:10.1007/s00127-010-0330-Z

[3] Ford, D.E. (2008) Optimizing outcomes for patients with depression and chronic medical illnesses. American Journal of Medicine, 121, S38-S44. doi:10.1016/j.amjmed.2008.09.012

[4] Mulsant, B.H. and Ganguli, M. (1999) Epidemiology and diagnosis of depression in late life. Journal of Clinical Psychiatry, 60, 9-15.

[5] Olver, J.S. and Hopwood, M.J. (2012) Depression and physical illness. Medical Journal of Australia. http://www.mja.com.au/open/2012/1/4/depression-and-ph ysical-illness

[6] Volkers, A.C., Nuyen, J., Verhaak, P.F.M. and Schellevis, F.G. (2004) The problem of diagnosing major depression 
in elderly primary care patients. Journal of Affective Disorders, 82, 259-263. doi:10.1016/j.jad.2003.11.003

[7] Barley, E.A., Murray, J., Walters, P. and Tylee, A. (2011) Managing depression in primary care: A meta-synthesis of qualitative and quantitative research from the UK to identify barriers and facilitators. BMC Family Practice, 12, 47.

[8] Zivin, K. and Kales, H.C. (2008) Adherence to depression treatment in older adults: A narrative review. Drugs Aging, 25, 559-571. doi:10.2165/00002512-200825070-00003.

[9] Kamphuis, M.H., Stegenga, B.T., Zuithoff, N.P., King, M., Nazareth, I., de Wit, N.J. and Geerlings, M.I. (2011) Recognition of depression in primary care: Does it affect outcome? The PREDICT-NL study. Family Practice. http://fampra.oxfordjournals.org/content/29/1/16.full.pdf +html?sid=bc58d487-d828-4630-b117-29a8cfe3f4d8

[10] Andersen, S.M. and Harthorn, B.H. (1989) The recognition, diagnosis, and treatment of mental disorders by primary care physicians. Medical Care, 27, 869-886. doi:10.1097/00005650-198909000-00003.

[11] Mitchell, A.J., Rao, S. and Vaze, A. (2011) Can general practitioners identify people with distress and mild depression? A meta-analysis of clinical accuracy. Journal of Affective Disorders, 130, 26-36. doi:10.1016/j.jad.2010.07.028

[12] McFarlane, A.C., Ellis, N., Barton, C., Browne, D. and Van Hooff, M. (2008) The conundrum of medically unexplained symptoms: Questions to consider. Psychosomatics, 49, 369-377. doi:10.1176/appi.psy.49.5.369

[13] Parker, G., Hilton, T., Hadzi-Pavlovic, D. and Bains, J. (2001) Screening for depression in the medically ill: The suggested utility of a cognitive-based approach. Australian and New Zealand Journal of Psychiatry, 35, 474-480. doi:10.1046/j.1440-1614.2001.00926.x

[14] Yesavage, J.A., Brink, T.L., Rose, T.L., Lum, O., Huang, V., Adey, M. and Leirer, V.O. (1983) Development and validation of a geriatric depression screening scale: A preliminary report. Journal of Psychiatric Research, 17, 3749. doi:10.1016/0022-3956(82)90033-4

[15] Nyunt, M.S., Fones, C., Niti, M. and Ng, T.P. (2009) Criterion-based validity and reliability of the Geriatric Depression Screening Scale (GDS-15) in a large validation sample of community-living Asian older adults. Aging Mental Health, 13, 376-382. doi:10.1080/13607860902861027

[16] Paradela, E.M., Lourenco, R.A. and Veras, R.P. (2005) Validation of geriatric depression scale in a general outpatient clinic. Revista de Saúde Pública, 39, 918-923.

\section{doi:10.1590/S0034-89102005000600008}

[17] Almeida, O.P. and Almeida, S.A. (1999) Short versions of the geriatric depression scale: A study of their validity for the diagnosis of a major depressive episode according to ICD-10 and DSM-IV. International Journal of Geriatric Psychiatry, 14, 858-865. doi:10.1002/(SICI)1099-1166(199910)14:10<858::AIDGPS35>3.0.CO;2-8

[18] D’Ath, P., Katona, P., Mullan, E., Evans, S. and Katona, C. (1994) Screening, detection and management of depression in elderly primary care attenders. I: The acceptability and performance of the 15 item Geriatric Depression Scale (GDS15) and the development of short versions. Family Practice, 11, 260-266. doi:10.1093/fampra/11.3.260

[19] Batstra, L., Bos, E.H. and Neeleman, J. (2002) Quantifying psychiatric comorbidity-lessions from chronic disease epidemiology. Social Psychiatry and Psychiatric Epidemiology, 37, 105-111. doi:10.1007/s001270200001

[20] Fortin, M., Bravo, G., Hudon, C., Vanasse, A. and Lapointe, L. (2005) Prevalence of multimorbidity among adults seen in family practice. The Annals of Family Medicine, 3, 223-228. doi:10.1370/afm.272

[21] Roberts, R.E., Kaplan, G.A., Shema, S.J. and Strawbridge, W.J. (1997) Prevalence and correlates of depression in an aging cohort: The Alameda County Study. Journals of Gerontology Series B: Psychological Sciences and Social Sciences, 52, S252-S258. doi:10.1093/geronb/52B.5.S252

[22] Australian Bureau of Statistics (2007) National Survey of Mental Health and Wellbeing: Summary of results. Australian Government, Canberra.

[23] Thompson, C., Ostler, K., Peveler, R.C., Baker, N. and Kinmonth, A.L. (2001) Dimensional perspective on the recognition of depressive symptoms in primary care: The Hampshire Depression Project 3. British Journal of Psychiatry, 179, 317-323. doi:10.1192/bjp.179.4.317

[24] Goldberg, D., Privett, M., Ustun, B., Simon, G. and Linden, M. (1998) The effects of detection and treatment on the outcome of major depression in primary care: A naturalistic study in 15 cities. British Journal of General Practice, 48, 1840-1844.

[25] Taylor, A.W., Price, K., Gill, T.K., Adams, R., Pilkington, R., Carrangis, N., Shi, Z., and Wilson, D. (2010) Multimorbidity: Not just an older person's issue. Results from an Australian biomedical study. BMC Public Health, 10, 718. doi:10.1186/1471-2458-10-718 